\title{
Variability of the bioluminescence characteristics of the Black Sea ctenophores-aliens in connection with different conditions of nutrition
}

\author{
Mashukova Olga*, Tokarev Yuriy \\ Department of the Biophysical Ecology, Kovalevsky Institute of Biology of the Southern Seas, National Academy of Sciences of \\ Ukraine, Sevastopol, Ukraine \\ Email: *olgamashukova@yandex.ru
}

Received 12 August 2013; revised 12 September 2013; accepted 1 October 2013

Copyright (C) 2013 Mashukova Olga, Tokarev Yuriy. This is an open access article distributed under the Creative Commons Attribution License, which permits unrestricted use, distribution, and reproduction in any medium, provided the original work is properly cited.

\begin{abstract}
Many ecological-physiological characteristics of ctenophores-aliens Mnemiopsis leidyi A. Agassiz, 1865 and Beroe ovata Mayer, 1912 are studied quite well because they play a very important ecological role in the Black Sea ecosystem. However, bioluminescence, one of the most important elements of the ctenophores ecology and its connection with feeding regime were not studied sufficiently. Experiments have shown that characteristics of the ctenophores bioluminescence differed considerably in dependence of food supplies. Thus, amplitude and light-emitting energy of the fed ctenophores $B$. ovata are maximal, 3 times more than analogical indices of the just-caught individuals and 4 times more than ones of starving individuals. More prolonged flash signal (to $3.5 \mathrm{~s}$ ), which exceeds light-emitting duration of the starving individuals twice, can be registered from the fed ctenophores. Investigation of the $M$. leidyi bioluminescence has shown that amplitude and light-emitting energy of the just-caught ctenophores were two times more than those of the starving individuals. At the same time, light-emitting amplitude of the fed individuals is 6.5 times and light-emitting energy is $3-4$ times higher than that of the just-caught ctenophores. The light-emitting duration of the starving and justcaught organisms is practically the same. The most prolonged signal is registered from the fed ctenophores-up to $2.8 \mathrm{~s}$. The data obtained testify that characteristics of the ctenophores bioluminescence can be conditioned not only by nutritional value but by the composition of the food as well.
\end{abstract}

Keywords: Bioluminescence; Beroe ovata; Mnemiopsis

"Corresponding author. leidyi; Black Sea; Nutrition

\section{INTRODUCTION}

Introduced to the Black Sea in 80 - 90 of the last century ctenophores Mnemiopsis leidyi A. Agassiz, 1865 and Beroe ovata Mayer, 1912 have made considerable impact on the Black Sea ecosystem. At the end of 80s'-beginning of 90s' years ctenophore Mnemiopsis leidyi, being transferred into the Black Sea water area with ballast waters, gave mass flash in abundance [1]. Together with other factors (climatic changes) this alien considerably influenced biomass of food mesoplankton, deteriorating food base of plankton-feeding fish - the base of the Black Sea fishery, pelagic fish [2].

For example, the sharp increase in number of $M$. leidyi has caused increase in a share of larval fish with empty stomachs that has led to the commercial fish population reducing by 1991 more than 5 times [3]. At the end of 90s' another ctenophore Beroe ovata invaded the Black Sea; which fed exclusively by mnemiopsis, and which meliorated the state of food base for planktonivorous fish and their larvae [4].

The processes of ctenophores life-activity (metabolism intensity, food uptake, composition of organic substance etc) are studied quite completely [5-7]. But there is practically no information about connection between the level of M. leidyi and B. ovata being fed and their bioluminescence under natural temperature conditions, as well as about optimal trophic conditions for the ctenophores bioluminescence [8-10].

Meanwhile, bioluminescence is one of the links in the organization of general metabolism in living systems, biochemical mechanisms of which try some modification under changes of surrounding conditions [11,12]. Ex- 
pressness and expressiveness of receiving information with the help of given test of organisms' resistance are undoubted advantages, if compared with criteria, used in marine planktonology. That's why the main task of our work was estimation of ctenophores $M$. leidyi and $B$. ovata light-emission characteristics changes in connection with conditions of their nutriation.

\section{MATERIAL AND METHODS}

Experimental studies of the food factor impact on the light-emitting parameters of ctenophores have been carried out in the Biophysical ecology department of IBSS of NASU: in July-August of 2006, and in October-November of 2007 and 2008 . Only freshly collected animals without any damage used for bioluminescence characteristics study. Total length $(\mathrm{mm})$ of ctenophores B. ovata and oral-aboral length $(\mathrm{mm})$ of $M$. leidyi were measured. Uni-sized (35 - $40 \mathrm{~mm}$ - for $M$. leidyi and $50 \mathrm{~mm}$-for $B$. ovata) animals within $1-2 \mathrm{~h}$ after catching were taken to the laboratory for the further adaptation to food experiments.

Ctenophores $M$. leidyi and B. ovata dependence on food supplies were divided into 3 groups: just-caught (control), fed and starving for two days specimens. In each group there were 40 individuals. The dry mass of ctenophore bodies was determined by weighing on the microanalitical weighs AN 50 precisely up to $0.1 \mathrm{mg}$ after drying at $60^{\circ} \mathrm{C}$, wet weight - by the volume of replaced brine in measuring cylinder. Dry mass of the studied bodies of ctenophore $M$. leidyi $-0.86 \pm 0.043 \mathrm{~g}$, B. ovata $-2.36 \pm 0.11 \mathrm{~g}$. Wet weight of $M$. leidyi-9.16 \pm 0.45, B. ovata- $10.88 \pm 0.54$ g. Ctenophores were kept in glass capacities by volume 3 - 51 with sea water, filtered through membrane filters with diameter of pores 35 $\mu \mathrm{m}$ in temperature $21 \pm 2^{\circ} \mathrm{C}[11]$.

Bioluminescence characteristics of the just-caught ctenophore - $M$. leidyi and B. ovata (1 group) were registered in $2 \mathrm{~h}$ after exposition, in the ctenophore of the second group (starving individuals) - in 2 days. M. leidyi were food object for B. ovata. To prepare third group of ctenophore for feeding beroe were set individually into 5-liter capacities with filtered brine. The food (mnemiopsis) were put 1 ind per each capacity after preliminary weighing. Then we observed food behavior of beroe. We fixed the time of capturing the prey and finish of digesting, directly after which we conducted stimulation of the ctenophore light emission. Copepoda Acartia tonsa Dana were an object of nutrition for M. leidyi, as, first, they dominate in the mesozooplankton composition at the second half of summer in the Sevastopol bay [13], and, second - in the food of the Black Sea mnemiopsis under natural conditions. That is why for feeding $M$. leidyi in experimental conditions we used calanoid copepoda Acartia tonsa Dana, grown in the fish cultivation laboratory, IBSS, NASU [14].

To support the given ctenophore feeding we brought into experimental vessels food organisms with concentration of copepoda $A$. tons $a-70$ ind $\cdot 1^{-1}$. Concentration of copepoda in the experimental vessels was determined before the beginning of the experiment by counting the individuals in an aliquot of volume in the Bogorov camera. Concentration of food organisms was corrected every day, keeping it at the level not less than $0.35 \mathrm{mg}$ of dry mass for $1^{-1}$. With such level of food supply ctenophores are quite mobile (swim actively) and maximally uptake oxygen, which supposes their ability in intensive bioluminescence [15].

The amplitude characteristics of the bioluminescence were investigated, using the laboratory complex "Light" [16]. The laboratory complex for studying the biophysical characteristics of ctenophores bioluminescence included a high-voltage power device (VS-22), luminescope, consisting of receiver of light radiation (FEU-71) and dark chamber for an object, and the digital registering device. Cuvette for mechanical and chemical (5 $\mathrm{cm}^{3}$ - for ctenophore) stimulation, in which experimental organisms were placed, is made of transparent plexiglas. Registration of ctenophores bioluminescence characteristics was conducted at full darkness. The biophysical characteristics of light-emission of $M$. leidyi were studied using mechanical and chemical stimulation.

For reception of irritation adequate to natural stimulus we used mechanical stimulation ctenophores [17]. The method of mechanical stimulation was reduced to creation of a stream of water in a vessel with bioluminescent by means of the pump electromechanical device. The changes of hydrophysical characteristics, caused by movement of water masses lead to deformation of ctenophores cellular membrane which, in turn, induced occurrence of potential of action and light-emission. To obtain of the information about maximal [18] ctenophores bioluminescent potential the method of chemical stimulation was used as well. By means of a syringe we entered into cuvette $3-5 \mathrm{~cm}^{3}$ of $96 \%$ of the ethyl alcohol chosen as chemical reagent. Amplitude, duration and full energy of flashes were compared in each group of individuals for equal temperature conditions $\left(21^{\circ} \mathrm{C} \pm 2^{\circ} \mathrm{C}\right)$.

\section{RESULTS AND DISCUSSION}

\subsection{Mnemiopsis leidyi Bioluminescence}

Experiments have shown that characteristics of the ctenophores $M$. leidyi и $B$. ovata bioluminescence differed considerably in dependence of food supplies. Dependence of the ctenophore $M$. leidyi bioluminescence characteristics on a degree of organisms being fed is shown at Figures 2 and 3. Investigation of M. leidyi bioluminescence has shown that amplitude and light-emit- 
ting energy of the just-caught ctenophores were two times more $(p<0.05)$, than that of the starving individuals (Figure 1).

At the same time, light-emitting amplitude of the fed species is 6.5 times and light-emitting energy is $3-4$ times higher than that of the just-caught ctenophores (Figures 2(a) and (b)).

The light-emitting durations of the starving and justcaught organisms were practically the same. The most prolonged signal is registered from the fed ctenophores M. leidyi-up to $2.8 \mathrm{~s}$ (Figure 2(c)).

Nutritive behavior of beroe is studied quite well $[19,20]$. In our investigations $90 \%$ of $B$. ovata individuals captured the prey (mnemiopsis), eating it in a whole if it was less in size, and other ate it, pulling it by pieces.

\subsection{Beroe ovata Bioluminescence}

Capture of food was observed averagely in $2 \mathrm{~h}$ after its setting there. Being eaten by beroe, ctenophore acquired a ball-form, and the time of digesting in experiments lasted averagely $4-5 \mathrm{~h}$. The characteristics of luminescence in the fed ctenophore beroe were studied after digesting of food and compared with those of the justcaught and starving individuals. Dependence of bioluminescence characteristics in ctenophore $B$. ovata on a degree of their organisms being fed is represented at Figure 3.

Maximal values of bioluminescence amplitude in the fed B. ovata 3 times exceeded analogous indices in the just-caught individuals (Figure 4(a)) and 4 times in two days starving organisms $(\mathrm{p}<0.05)$.

Indices of energy in the just-caught, fed and starving individuals also differ considerably (Figure 4(b)).

The energy of light emission reaches highest values in the fed ctenophore, making $(348.35 \pm 17.41) \cdot 10^{8}$ quantum $\mathrm{cm}^{-2}$, which is 4 times higher than analogous indices in the just-caught organisms. But energetic indices in the

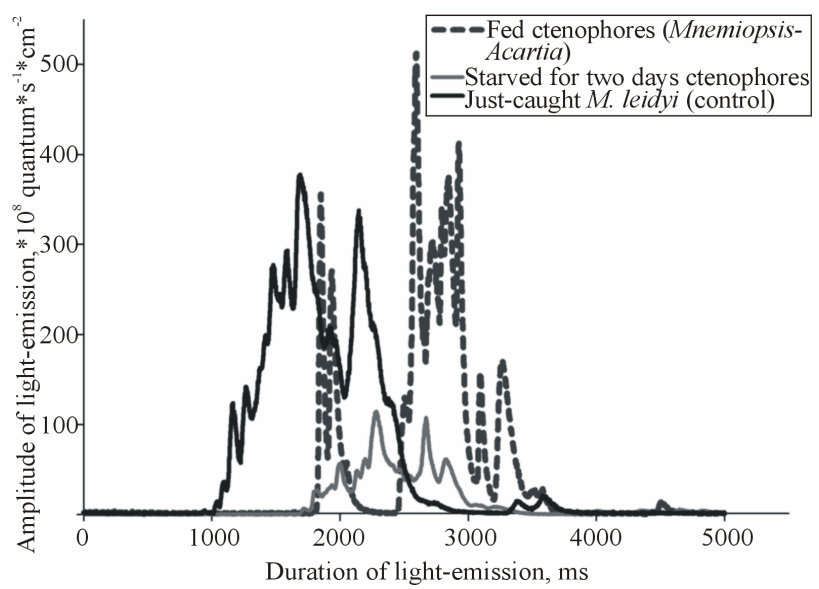

Figure 1. The typical bioluminescence signals of $M$. leidyi under different nutrition conditions.

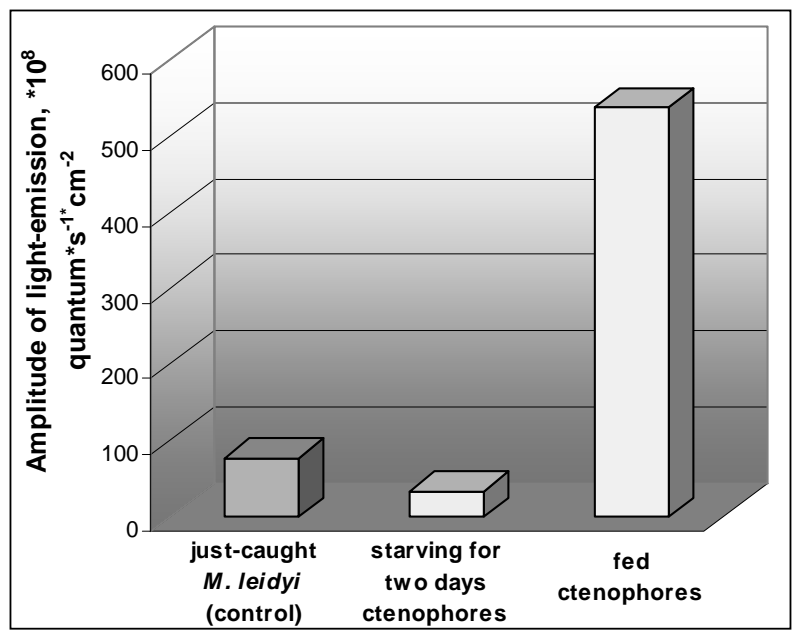

(a)

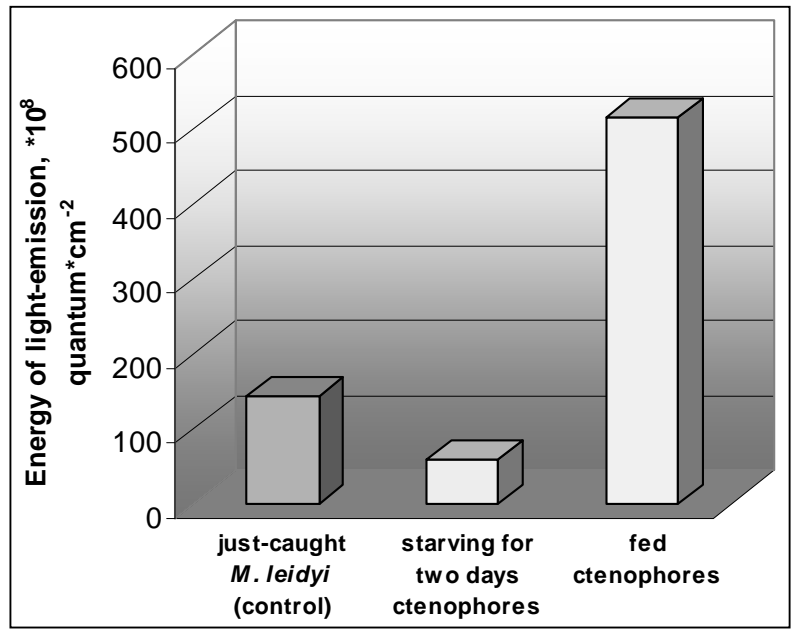

(b)

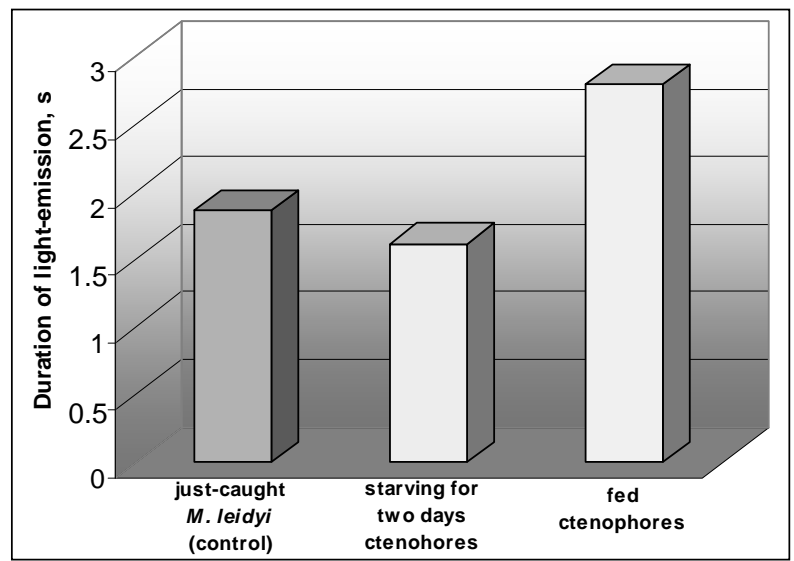

(c)

Figure 2. (a) The statistical estimation of the light-emission amplitude ratio of just-caught, starving for two days and fed ctenophores M. leidyi; (b) The statistical estimation of the light-emission energy ratio of just-caught, starving for two days and fed ctenophores M. leidyi; (c) The statistical estimation of the light-emission duration ratio of just-caught, starving for two days and fed ctenophores M. leidyi. 


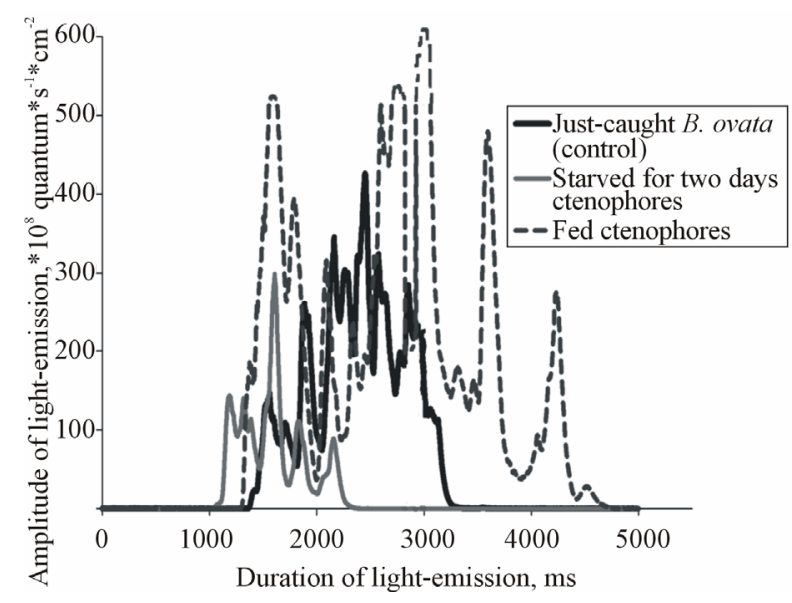

Figure 3. The typical bioluminescence signals of B. ovata under different nutrition conditions.

just-caught ctenophores are 2.5 times higher than in starving individuals, making $(122.82 \pm 6.14) \cdot 10^{8}$ quantum $\mathrm{cm}^{-2}$ - under mechanical stimulation and $(81.10 \pm$ $3.24) \cdot 10^{8}$ quantum $\cdot \mathrm{cm}^{-2}$ - under chemical one.

It is known that bioluminescence characteristics in ctenophores differ considerably under different types of stimulation [21]. In the given investigations, they observed the highest magnitudes of the light emission amplitude and energy in the fed individuals $M$. leidyi under chemical stimulation, and in the fed individuals $B$. ovata - under mechanical stimulation.

Flashes duration of just-caught and fed individuals (Figure 4(c)) is practically the same.

But more long flash signal-up to $3.5 \mathrm{~s}$, especially under the mechanical stimulation, can be observed in the fed ctenophores, and that exceeds twice $(p<0.05)$ time of light emission by the starving for two days individuals. Thus, maximal energy and time indices of bioluminescence in M. leidyi as well as B. ovata are registered in the fed species and minimal - in starving ctenophores.

We may suppose that the most intensive luminescence of the fed and just-caught ctenophores is conditioned by the fact that level of oxygen consumption by them makes maximal values [16]. For example, the oxygen consumption intensity in starving individuals decrease considerably during two days [22], due to the energetic parameters of their bioluminescence (amplitude, in particular) decrease too.

In addition, taking into account the change of ctenophores biochemical composition depending on a degree of their being fed [23] and biochemical nature of bioluminescent reactions we can explain the registered changes of ctenophores biophysical light-emission characteristics by a change in food supplies. Observed in experiments depressed condition of ctenophores in connection with starvation and minimal indices of their bioluminescence can be explained by decrease in content of re-

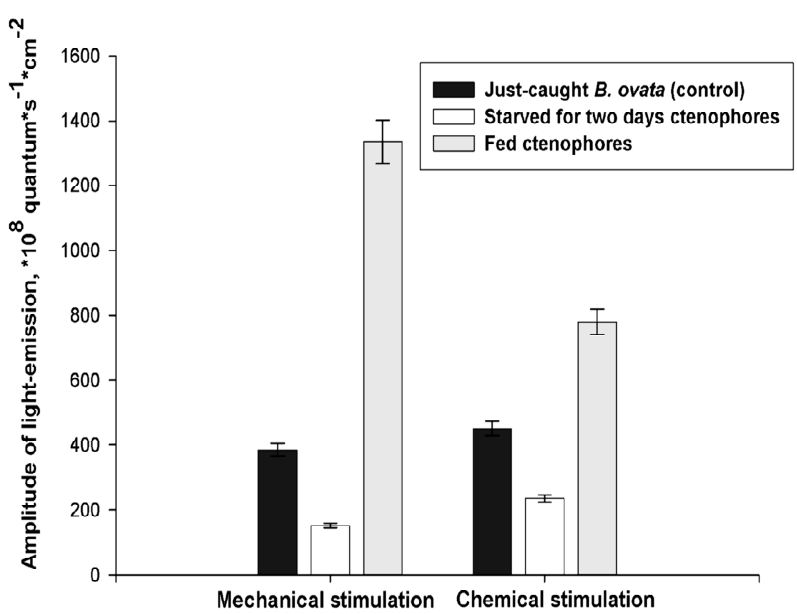

(a)

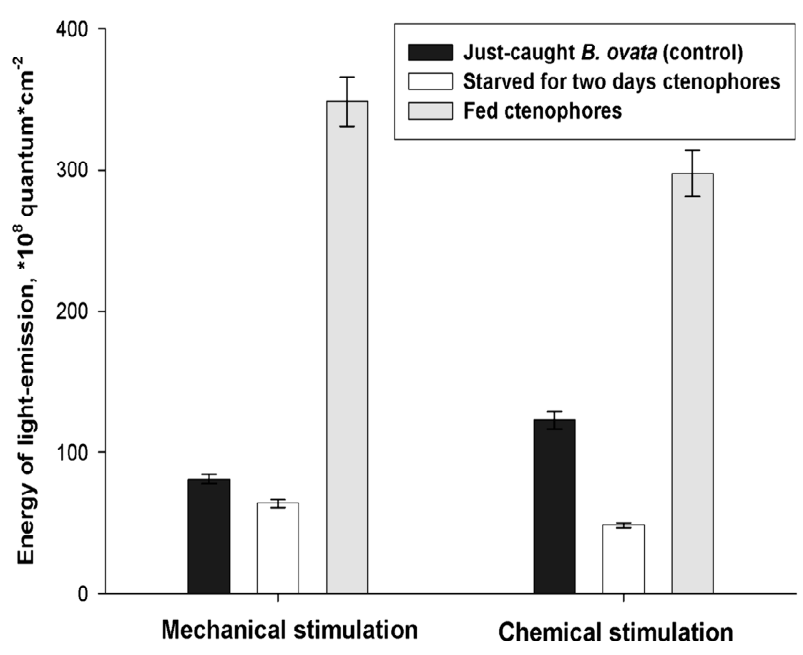

(b)

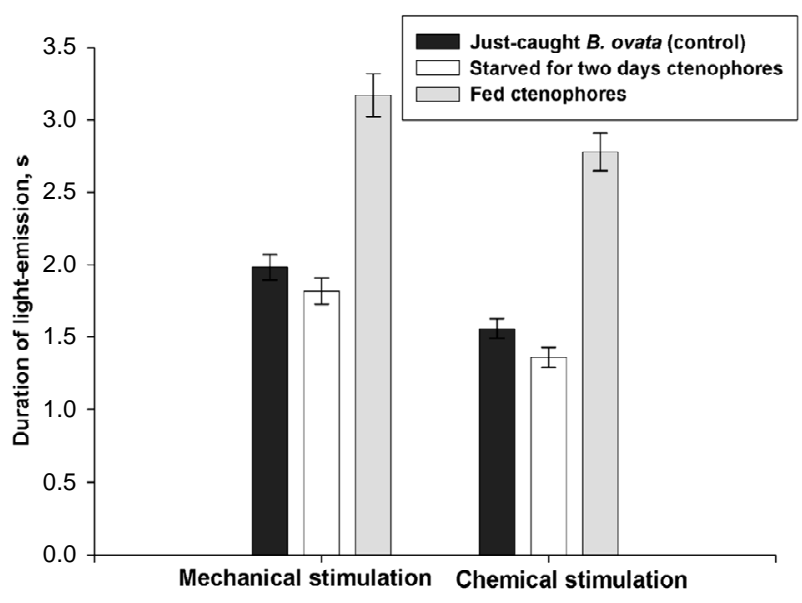

(c)

Figure 4. (a) The statistical estimation of the light-emission amplitude ratio of just-caught, starving for two days and fed ctenophores B. ovata; (b) The statistical estimation of the energy of light-emission ratio of just-caught, starving for two days and fed ctenophores B. ovata; (c) The statistical estimation of the light-emission duration ratio of just-caught, starving for two days and fed ctenophores B. ovata. 
served polysaccharide-glycogen. The glycogen content in polysaccharides, reaching maximum in the justcaught organisms (76.0 - in B. ovata and $86.6 \%$ in $M$. leidyi) reduced substantially under starvation: to $34.4 \%$ in B. ovata and $18.3 \%$ in M. leidyi. Monosaccharide content under starvation of ctenophores decreases from $39.9 \%$ to $13.5 \%$ in B. ovata and from $45.8 \%$ to $14.3 \%$ in M. leidyi [22]. Fed ctenophores as M. leidyi, as B. ovata, with ample being fed have maximal concentrations of organic matter; therefore, in the time of light-emission they give the most intensive flash. Studied dependences of ctenophores light-emission characteristics on food supply make essential contribution to the exposure of consistent patterns of trophic cooperations predator-prey, important at the research of water organisms and ecosystems functioning.

\section{ACKNOWLEDGEMENTS}

The authors express sincere gratitude for help in experiments with $M$. leidyi to A. N. Khanaychenko, the leading scientist of the IBSS of NAS of Ukraine.

\section{REFERENCES}

[1] Mutlu, E. (1999) Distribution and abundance of ctenophores and their zooplankton food in the Black Sea. II: Mnemiopsis leidyi, Marine Biology, 135, 603-613. http://dx.doi.org/10.1007/s002270050661

[2] Gucu, A.C. (2002) Can overfishing be responsible for the successful establishment of Mnemiopsis leidyi in the Black Sea? Estuarine, Coastal and Shelf Science, 54, 439-451. http://dx.doi.org/10.1006/ecss.2000.0657

[3] Gordina, A.D., Tkach, A.V., Pavlova, E.V., et al. (2003) Condition of ichthyoplankton communities in the Sevastopol Bay (Crimea) in the May-September 1998 и 1999. Questions of the Ichthyology, 43, 184-193.

[4] Shushkina, E.A., Musaeva, E.I., Anochina, L.L., et al. (2000) Role of the jellyfish macroplankton: Sifonophore Aurelia aurita, ctenophores Mnemiopsis leidyi and Beroe ovata in the planktonic community of the Black Sea. Oceanologiya, 40, 859-861.

[5] Kremer, P. (1982) Effect of food availability on the metabolism of the ctenophore Mnemiopsis mccradyi. Marine Biology, 71, 149-156. http://dx.doi.org/10.1007/BF00394623

[6] Sullivan, L.J. and Gifford, D.J. (2009) Preservation of the larval ctenophore Mnemiopsis leidyi A. Agassiz (Ctenophora, Lobata). Journal of Plankton Research, 31, 921926. http://dx.doi.org/10.1093/plankt/fbp031

[7] Thuesen, E.V., Rutherford Jr., L.D. and Brommer, P.L. (2005) The role of aerobic metabolism and intragel oxygen in hypoxia tolerance of three ctenophores: Pleurobrachia bachei, Bolinopsis infundibulum and Mnemiopsis leidyi. Journal Marine Biology Association U.K., 85, 627-633. http://dx.doi.org/10.1017/S0025315405011550

[8] Girsch, S.J. and Hastings, J.W. (1978) The properties of mnemiopsin, a bioluminescent and light sensitive protein purified by hollow fiber techniques. Molecular and Cellular Biochemistry, 19, 113-124. http://dx.doi.org/10.1007/BF00232600

[9] Haddock, S.H.D., Moline, M.A. and Case, J.F. (2010) Bioluminescence in the Sea. Annual Review of Marine Science, 2, 443-493.

http://dx.doi.org/10.1146/annurev-marine-120308-081028

[10] Shimomura, O. (2006) Bioluminescence: Chemical principles and methods. World Scientific.

[11] Mashukova, O.V. and Tokarev, Yu.N. (2012) Influence of the temperature at the Black Sea ctenophores-aliens bioluminescence characteristics. Advances in Bioscience and Biotechnology, 3, 269-273. http://dx.doi.org/10.4236/abb.2012.33037 http://www.scirp.org/journal/abb/

[12] Lapota, D. (2012) Bioluminescence-Recent advances in oceanic measurements and laboratory applications. InTech Janeza Trdine, 9, 190.

[13] Gubanova, A.D. (2003) Long-time changebilities in the zooplankton community of the Sevastopol Bay. In: Eremeev, V.N. and Gaevskaya, A.V., Eds., Modern Condition of the Biodiversity Neritic Water Crimea. EKOSYGydrophysica. NAN of the Ukraine, InBSS, Sevastopol.

[14] Mashukova, O.V., Khanaychenko, A.N., Tokarev, Yu.N., et al. (2008) The influence of nutrition on the bioluminescence characteristics of ctenophore Mnemiopsis leidyi. Ekologiya Morya, 75, 42-47.

[15] Finenko, G.A., Abolmasova, G.I. and Romanova, Z.A. (1995) Nutrition, oxygen consumption and grow of ctenophore Mnemiopsis mccradyi in dependence of feed concentration. Biology of the Sea, 21, 315-320.

[16] Tokarev, Yu.N., Bityukov, E.P., Vasilenko, V.I., et al. (2003) Specimen's diversity of the planktonic bioluminescents in the Black sea and characteristics of forming by them bioluminescence field in the neritic aquatoria. In: Eremeev, V.N. and Gaevskaya, A.V., Eds., Modern Condition of the Biodiversity Neritic Water Crimea. EKOSYGydrophysica. NAN of the Ukraine, InBSS, Sevastopol.

[17] Tokarev, Yu.N. (2006) Basin of hydrobionts biophysical ecology. ECOSI-Hydrophysics, Sevastopol.

[18] Borodin, D.V. (2002) The bioluminescence stimulation of the sea dinophlagellates: Analyze of the method. Ekologiya Morya, 60, 88-93.

[19] Finenko, G.A., Romanova, Z.A. and Abolmasova, G.I. (2000) The new ctenophore-introducer to the Black Sea-Ctenophore Beroe ovata Brunguiere. Ekologiya Morya, 50, 21-25.

[20] Vostokov, S.V., Arashkevich, E.G., Drith, A.V., et al. (2001) Ecological-physiological characteristics of the ctenophore Beroe ovata in the neritic aquatoria of the Black Sea: abundance, biomass, size characteristics of population, behavior, nutrition and metabolism. Oceanology, 41, 109-115.

[21] Tokarev, Yu.N., Mashukova, O.V. and Vasilenko, V.I. (2008) The bioluminescence of the Black-seas ctenophores-aliens Mnemiopsis leidyi and Beroe ovata under mechanical and chemical stimulation. Ekologiya Morya, 
76, 61-65.

[22] Anninsky, B.E., Finenko, G.A., Abolmasova, G.I., et al. (2005) Effect of starvation on the biochemical compositions and respiration rates of ctenophores Mnemiopsis leidyi and Beroe ovata in the Black Sea. Journal Marine
Biology Association U.K., 85, 549-561. http://dx.doi.org/10.1017/S0025315405011471

[23] Anninsky, B.E. (1994) Organic matter content of sifonophore Aurelia aurita and two ctenophores specimens of the Black Sea. Biology of the Sea, 20, 291-295. 